International Journal of Automotive and Mechanical Engineering (IJAME)

ISSN: 2229-8649 (Print); ISSN: 2180-1606 (Online); Volume 7, pp. 1074-1085, January-June 2013

(C)Universiti Malaysia Pahang

DOI: http://dx.doi.org/10.15282/ijame.7.2012.22.0087

\title{
A PRACTICAL APPLICATION OF ENSEMBLE AVERAGED SURFACE NORMAL IMPEDANCE MEASURED IN SITU
}

\author{
Nazli Che Din ${ }^{1, *}$, Toru Otsuru ${ }^{2}$, Reiji Tomiku², Mohd Zamri Jusoh ${ }^{3}$ and Mohamad \\ Ngasri Dimon ${ }^{4}$ \\ ${ }^{1}$ Faculty of Built Environment, University of Malaya, 50602, Kuala Lumpur, Malaysia \\ Email: nazlichedin@um.edu.my \\ ${ }^{2}$ Department of Architecture and Mechatronics, Faculty of Engineering, Oita University, \\ 700 Dannoharu, Oita 870-1192, Japan \\ ${ }^{3}$ Faculty of Electrical Engineering, Universiti Teknologi MARA (Terengganu), Sura \\ Hujung, 23000 Dungun, Terengganu, Malaysia \\ ${ }^{4}$ Radio Communication Engineering Department, Faculty of Electrical Engineering, \\ Universiti Teknologi Malaysia, 81310 Skudai, Johor, Malaysia
}

\begin{abstract}
This paper presents the application of an in situ measurement technique of sound absorption characteristics, namely the "Ensemble Averaged Method". Previously, a measurement technique of material surface normal impedance by using a twomicrophone (p-p) technique and ambient noise was proposed by some of the authors. This includes the concept of "ensemble averaged" surface normal impedance to extend the usage of the obtained values to various applications, such as architectural acoustics and computational simulations. With the development of a particle velocity ( $p-u)$ sensor, the practicality of techniques for the direct measurement of impedance becomes feasible. A concept of the ensemble averaged surface normal impedance is addressed, including a basic technique to measure it by using $\mathrm{p}-\mathrm{p}$ and $\mathrm{p}-\mathrm{u}$ sensors. Then, the agreements between $\mathrm{p}-\mathrm{p}$ and $\mathrm{p}-\mathrm{u}$ sensors are discussed and the discrepancies of absorption coefficients are shown to be small. The paper reveals the reliability, applicability and feasibility of the method throughout the investigation as an in situ measurement technique.
\end{abstract}

Keywords: In situ technique; ensemble average; normal impedance; absorption coefficient.

\section{INTRODUCTION}

Numerous in situ measurement techniques have been proposed to measure sound absorption characteristics. There are two well-known methods of laboratory measurement of absorption, which have been described as international standards (ISO 105034, 1996; ISO 10534, 1998; ISO 354, 2003) in providing important databases regarding test materials, i.e., the reverberation room, and the tube method. A number of studies (Kosten, 1960; Makita et al., 1968a; Makita et al., 1968b; Cummings, 1991; Iwase and Izumi, 1995; Horoshenkov et al., 2007) have been conducted in order to check the effectiveness of the standard. Nevertheless, there are still issues that remain unresolved, e.g., the difficulty of measurements in situ because similar mounting conditions are difficult to reproduce. 

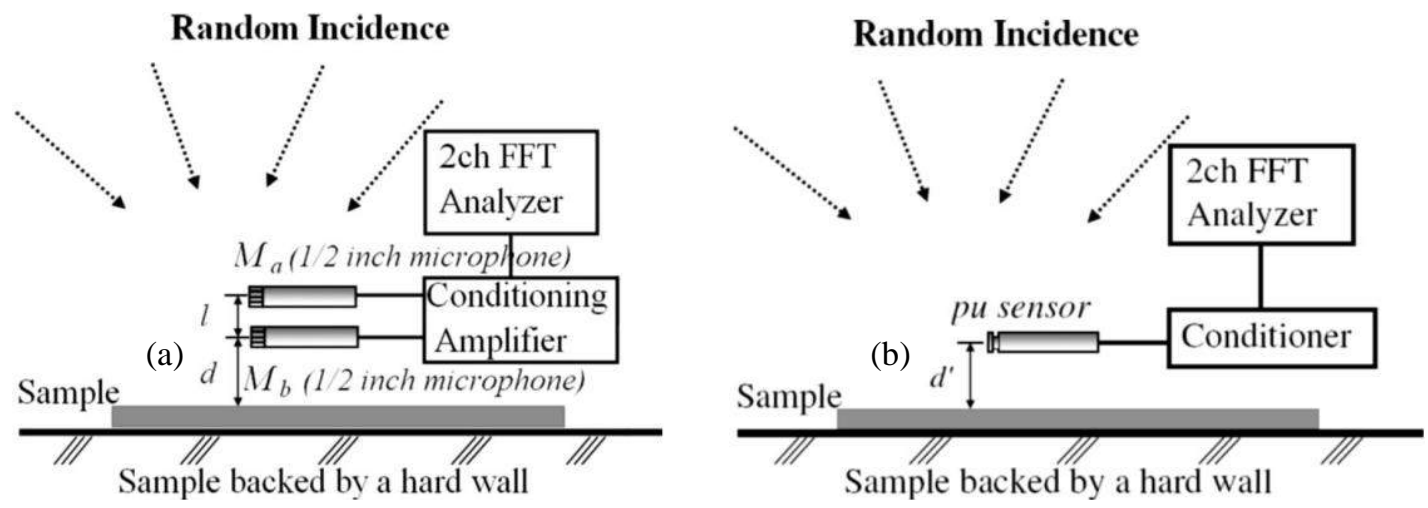

Figure 1. Schematic diagram of the measurement setup by using: (a) p-p sensor, and (b) p-u sensor.

On the other hand, numerous methods have been proposed to measure the absorption characteristics of material in situ. One of most popular methods it the "reflection method", which has been used to derive the sound absorption coefficient in situ. Among the works in the literature on the reflection method, Garai (1993) applied the maximum length sequential (MLS) technique as a test signal to improve the immunity to background noise and to measure the absorption coefficient in situ. However, there are restrictions of the method at low frequencies because the assumption of the plane wave is unachievable. Thus, the method proposed by Allard and Champoux (1989) is popular and efficient among the reflection methods. Their method focuses on a transfer function method using two microphones (p-p) located near the surface and this enables in situ measurements of a sample area. Nevertheless, the required sample size increases as the frequency decreases. To overcome this situation, some authors have proposed a method using a two microphones technique with Environmental Anonymous Noise as the sound source; known as "the EA method" (Takahashi et al., 2005). Initially, the sound source was intended for use only with diffuse ambient noise that exists around the specimen to be measured. However, in cases where this is insufficient, a supplemental noise source(s) can be added to improve the result.

Meanwhile, with the development of a particle velocity sensor, i.e., Microflown $^{\mathrm{TM}}$, alternative measurement techniques have become possible for direct related particle velocities quantities (de Bree et al., 2006). Aiming towards a simple and efficient in situ measurement technique, the authors make use of the combination of a microphone and a particle velocity ( $\mathrm{p}-\mathrm{u}$ ), instead of a two microphones technique, in order to determine the acoustic behavior of absorption material in the EA method. This paper is structured as follows: Section 2 presents the description of the EA method for each type of sensor. Section 3 discusses the results obtained by practical measurement with different types of sensor. Section 4 presents the preliminary results for the absorption coefficient of in situ measurements, i.e., in architectural spaces and in car cabins. Section 5 shows that the method is applicable for absorption characteristics of perforated-type panels, and Section 6 concludes the paper. 


\section{ENSEMBLE AVERAGE METHOD}

\section{Outline of the Method using p-p Sensor}

The technique described below is based on the measurement of the pressure transfer function between two microphones. As shown in Figure 1(a), two $1 / 2$ inch microphones are located at $\mathrm{M}_{\mathrm{a}}$ and $\mathrm{M}_{\mathrm{b}}$. The distance $d$ from the material surface is about $10 \mathrm{~mm}$; the space $l$ between the two microphones is $13 \mathrm{~mm}$. The transfer function $H_{\mathrm{ab}}(\omega)$ between $p_{\mathrm{a}}(\omega)$ and $p_{\mathrm{b}}(\omega)$ at $\mathrm{M}_{\mathrm{a}}$ and $\mathrm{M}_{\mathrm{b}}$ is measured by means of a Fast Fourier Transform (FFT) analyzer. When ambient noise is utilized as the sound source with the sound pressure $p_{\mathrm{aEA}}(\omega)$ and $p_{\mathrm{bEA}}(\omega)$ under the plane wave assumption, the normal impedance ratio of material to air $Z_{E A}(\omega)$ is given as (here, time dependence $e^{j \omega t}$ is omitted):

$$
Z_{E A}(\omega)=\rho c \frac{H_{a b E A}(\omega)\left(1-e^{2 j k(l+d)}\right)-e^{j k l}\left(1-e^{2 j k d}\right)}{H_{a b E A}(\omega)\left(1+e^{2 j k(l+d)}\right)-e^{j k l}\left(1+e^{2 j k d}\right)},
$$

where $k$ is the wavelength constant, and $j$ is an imaginary unit. If the ambient noise is insufficient, a supplemental sound source can be added to improve the signal-to-noise ratio.

\section{Outline of the Method using p-u Sensor}

If a p-u sensor is applied to the EA method (Figure 1(b)) instead of a p-p sensor, it can be located at the same position of $\mathrm{M}_{\mathrm{b}}$ in Figure 1(a). Surface normal impedance of a material is simply defined as:

$$
Z_{n}=\frac{p_{\text {surf }}}{u_{n, \text { surf }}}
$$

where $u$ and $p$ are normal particle velocity and sound pressure at the material surface, respectively.

Our previous paper (Otsuru et al., 2009) introduced impedance $\left\langle Z_{n}\right\rangle$ that is an ensemble averaged impedance over a sufficient number of incoherent sound sources such as to expect random incidence. Consequently, the following equations are expected to yield a statistically good approximation of the surface normal impedance and corresponding absorption coefficient of a specimen.

$$
\begin{gathered}
\left\langle Z_{n}\right\rangle=\frac{\left\langle p_{\text {surf }}\right\rangle}{\left\langle u_{n, \text { surf }}\right\rangle} \\
\langle\alpha\rangle=1-\left|\frac{\left\langle Z_{n}\right\rangle-\rho c}{\left\langle Z_{n}\right\rangle+\rho c}\right|^{2}
\end{gathered}
$$

In a practical measurement, to achieve sufficient averaging, the authors propose the following:

$$
\left\langle Z_{n}\right\rangle=\frac{1}{N} \sum_{N} \frac{\langle\tilde{p}\rangle}{\left\langle\tilde{u}_{n}\right\rangle}
$$




\section{COMPARISON OF TWO DIFFERENT MEASUREMENT PRINCIPLES}

\section{Measurement Framework}

A series of absorption characteristic measurements was conducted by use of the EA method with both p-p and p-u sensors, as shown in the schematic diagram of the measurement setup (Figure 1). The measurement of the p-p sensor, the transfer function $H_{a b}(\omega)$ between the sound pressures at the two microphones $p_{a}$ and $p_{b}$, was measured. Then, if a $\mathrm{p}-\mathrm{u}$ sensor is applied to the measurement instead of the $\mathrm{p}-\mathrm{p}$ sensor, it can be located $10 \mathrm{~mm}$ above the surface to measure $p$ and $u_{n}$. Prior to detailed investigations, a refinement of the calibration system by use of an impedance tube of $10-\mathrm{cm}$ diameter was conducted and the basic characteristics of the $\mathrm{p}-\mathrm{u}$ sensor were measured. The resolution of two channels FFT (RION SA-78) is set to $1.25 \mathrm{~Hz}$ and a Hanning window with a $0.8 \mathrm{~s}$ time length is employed to measure the transfer function. Linear averaging in the frequency domain is performed $N=150$ times. The measurements were conducted in a reverberation room (Room I) at the Information Center of Oita University. For the random incidence condition, six loudspeakers (Fostex FE-103) mounted in small boxes were used to radiate incoherent pink noise. The pink noise is filtered to eliminate unnecessary frequency components and to focus on 100 to $1000 \mathrm{~Hz}$. A sub-woofer (JVC SX-DW77) is also added to increase the low frequency energy roughly below $200 \mathrm{~Hz}$.

\section{Results of Absorption Coefficients}

In Room I, the absorption characteristics of two specimens of glass wool: GW50, 50$\mathrm{mm}$ thick, and GW25, 25-mm thick, were measured with different types of sensors. The sensor position was fixed at the center of $0.9 \times 1.8 \mathrm{~m}$ specimen. The corresponding absorption coefficients of GW50 obtained using measurements are compared in Figure 2(a). The agreements of absorption coefficients are good. Similarly, those for GW25 are compared in Figure 2(b). Slight discrepancies of about 0.05 are observed in the absorption coefficients. The discrepancies between the two methods can be regarded as resulting mainly from differences in the measuring mechanism of the particle velocity between the sensor types. The method using the $\mathrm{p}$-u sensor is expected to give better results because the configuration is simpler. At this point, the authors conclude that, our method offers satisfactorily equivalent absorption coefficient for the specimens tested with either type of sensor.

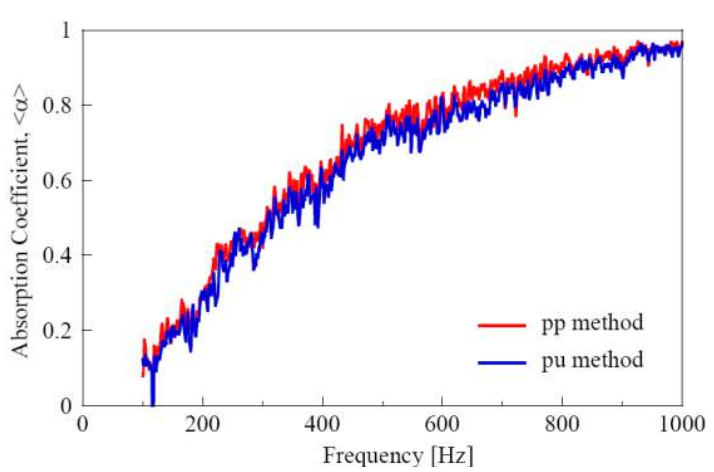

(a)

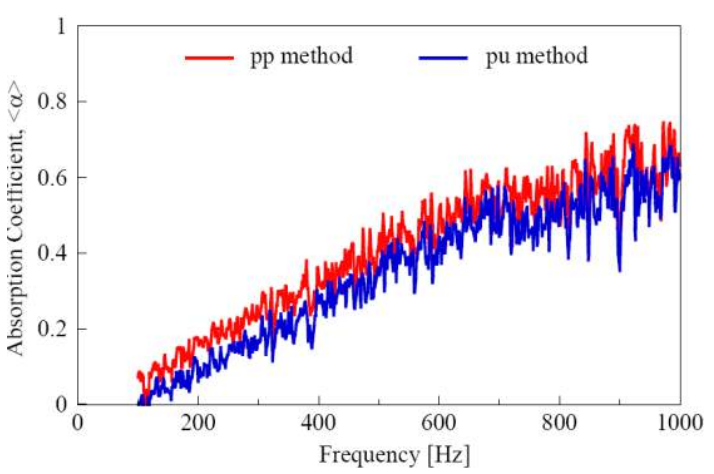

(b)

Figure 2. Comparison of absorption coefficients obtained by $\mathrm{p}-\mathrm{p}$ and $\mathrm{p}-\mathrm{u}$ sensor:

(a) GW50, and (b) GW25. 


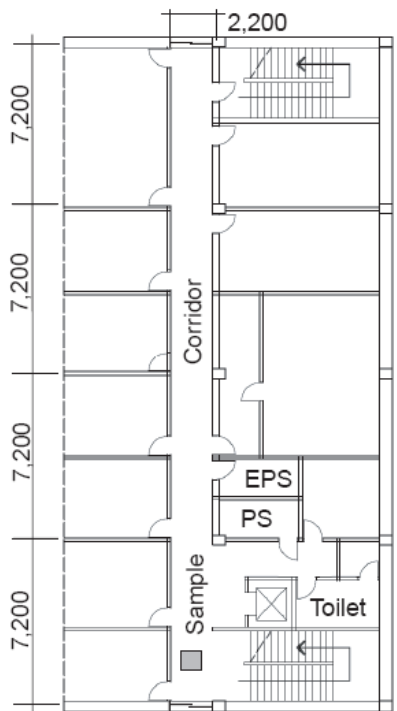

a (i)

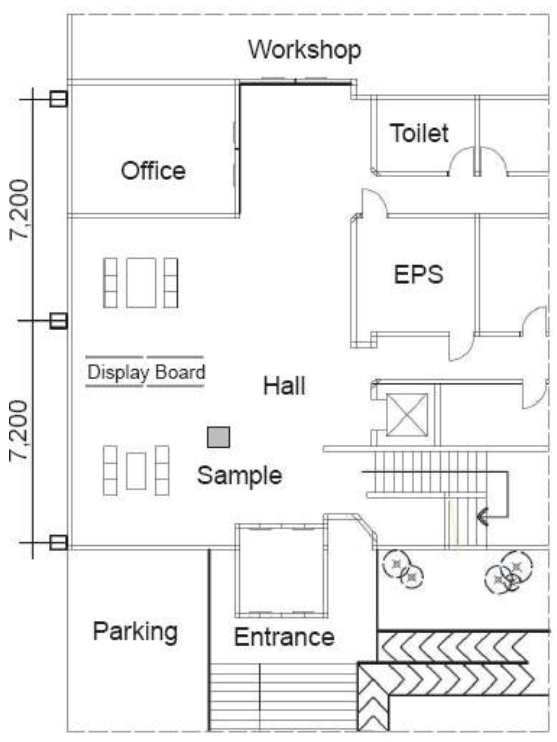

b (i)

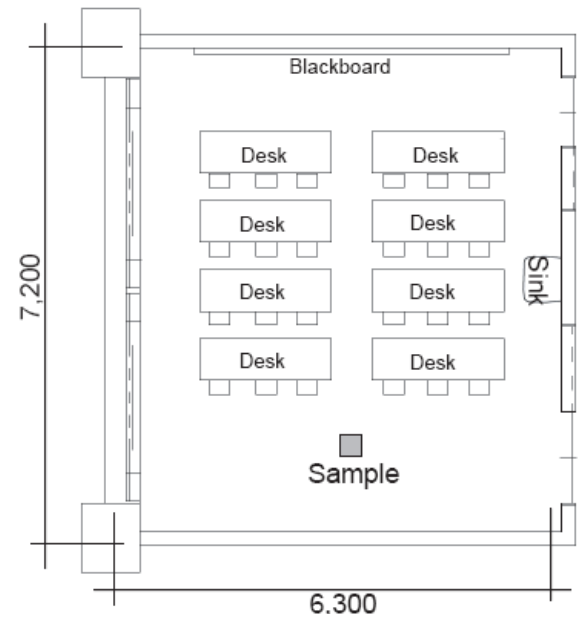

c (i)

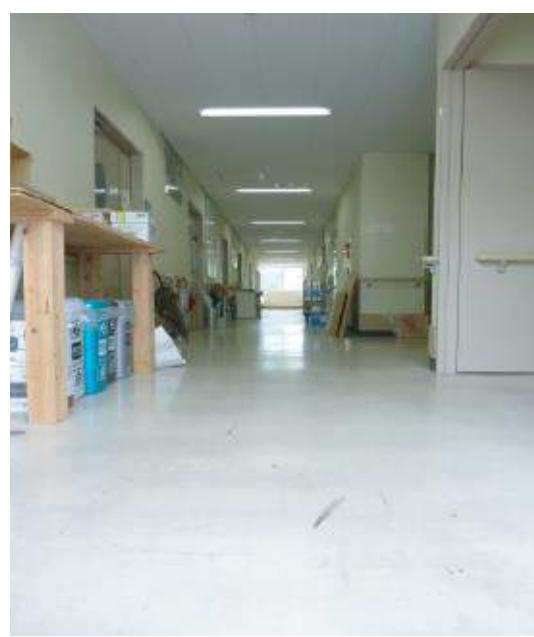

a (ii)

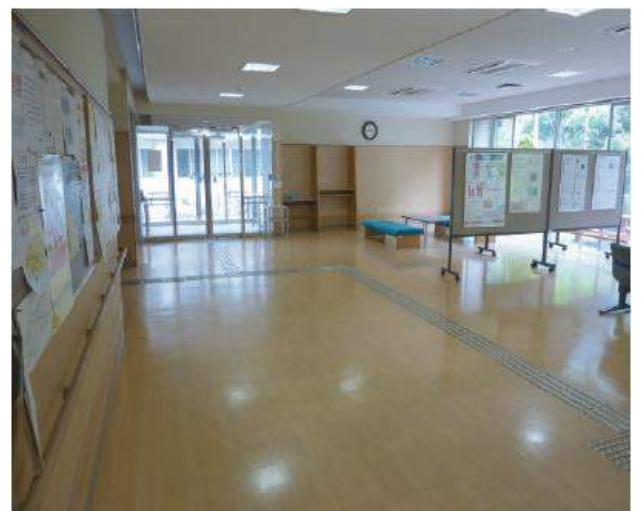

b (ii)

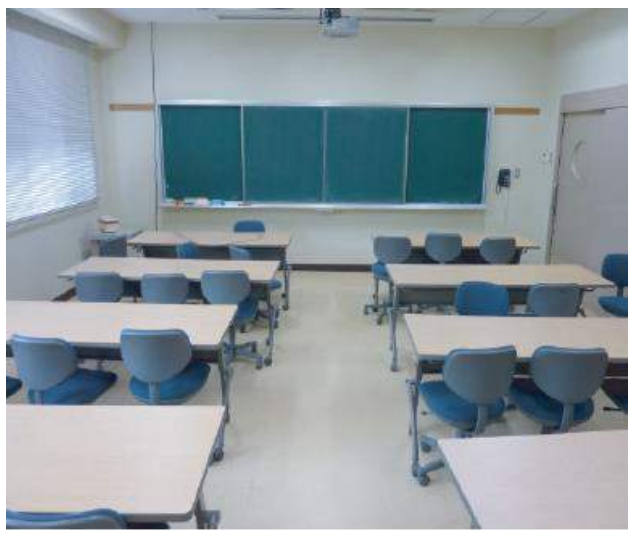

c (ii)

Figure 3. Plan views and photos of field measurement in architectural spaces: (a) a corridor, (b) an entrance hall, and (c) a seminar room 


\section{APPLICATION ON IN SITU MEASUREMENT}

\section{Architectural Spaces}

To investigate the general applicability of the proposed method, a series of preliminary measurements of the two different measurement principles was carried out in three architectural space environments (a corridor, an entrance hall, and a seminar room). Photos and plan views of the furniture layouts with material locations in the field measurements are shown in Figure 3. The specimen investigated is GW50. The specimen is laid on a $0.02-\mathrm{m}$ acrylic plate and has the same square area of $0.6 \mathrm{~m}^{2}$. The specimen's sizes are not exactly identical to that of the investigation in the previous section, but we expected to have sufficient validity for the discussion, as described by Nazli et al. (2012). Six portable sound speakers with incoherent pink noise are employed and manually moved randomly by three people to realize the random noise conditions because of insufficient noise within all three environmental conditions. For comprehensible comparisons, the measurements of similar specimens are conducted in Room I using six fixed loudspeakers to radiate incoherent pink noise.

Figures 4 and 5 present the combined results of the corresponding absorption coefficients and normalized impedances obtained by both the $\mathrm{p}-\mathrm{p}$ and $\mathrm{p}-\mathrm{u}$ methods in three other environments for GW50, respectively. All the measured absorption characteristics in the three other environments are compared with the measured absorption coefficients obtained in Room I. The maximum differences and mean deviation of the measured absorption coefficients are provided in Figure 6(a) and 6(b), respectively. The similar basic tendencies of absorption characteristics can be observed for GW50 in Figures 4 and 5, but there are noticeable differences in the dispersion that can be observed below $250 \mathrm{~Hz}$ in the impedance results. There can be complementary aspects, which can explain this phenomenon: (i) influences of room modes, and (ii) the dissimilarity of the measurement setting of sound sources where the fixed loudspeakers are employed in Room I. Moreover, both methods can be considered as having fair agreement based on the maximum dispersion being below 0.17 and the maximum mean deviation being lower than 0.06. The authors consider the dispersion of measured absorption coefficients yield plausible agreements that support the applicability of the proposed method in various sound fields.

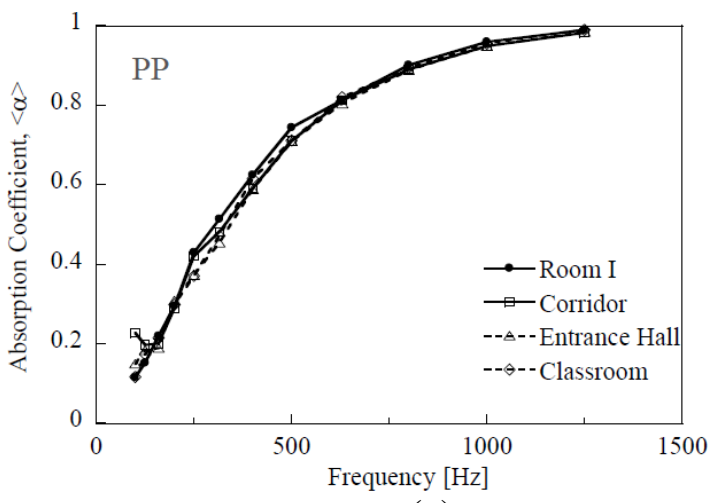

(a)

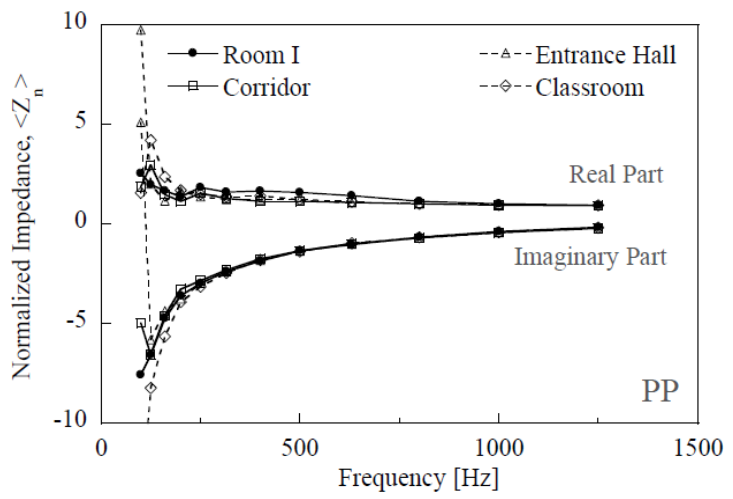

(b)

Figure 4. Comparison of measured absorption characteristics of GW50 obtained by p-p sensor in the reverberation room (Room I), the corridor, the entrance hall, and the seminar room. 


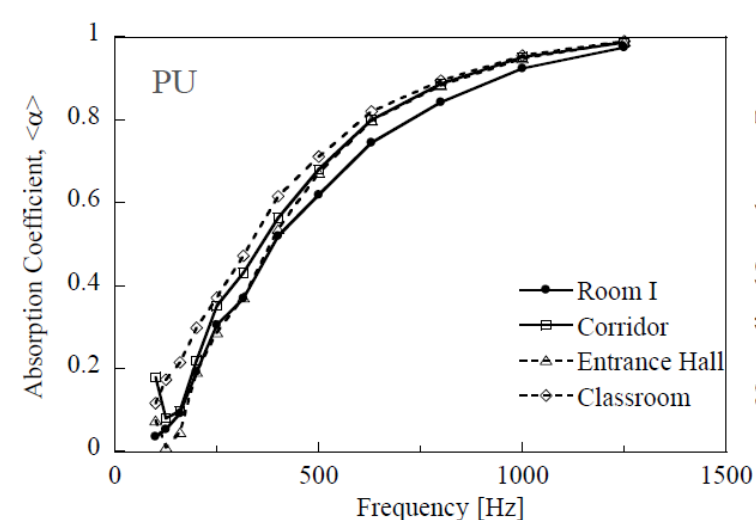

(a)

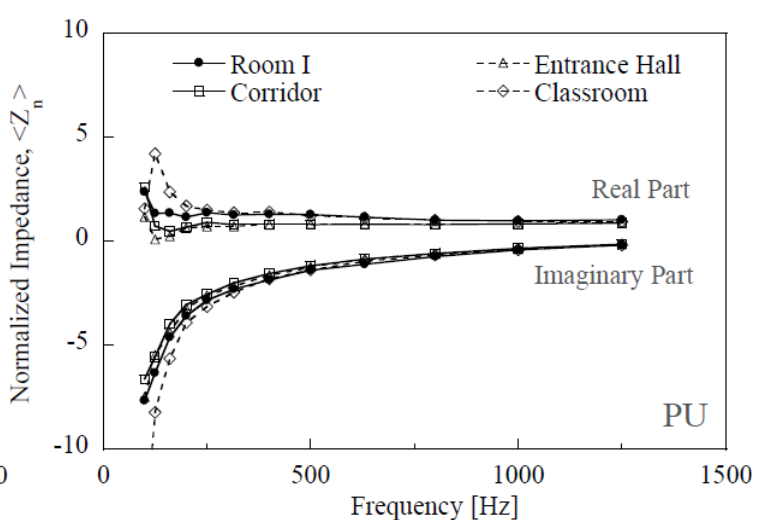

(b)

Figure 5. Comparison of measured absorption characteristics of GW50 obtained by p-u sensor in the reverberation room (Room I), the corridor, the entrance hall, and the seminar room.

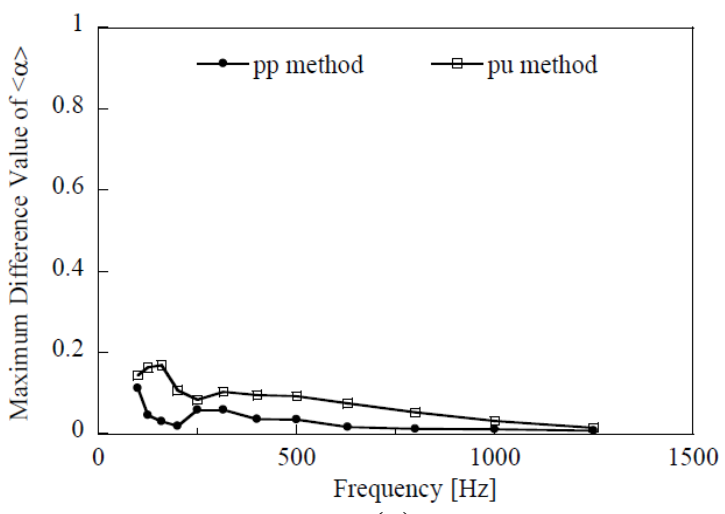

(a)

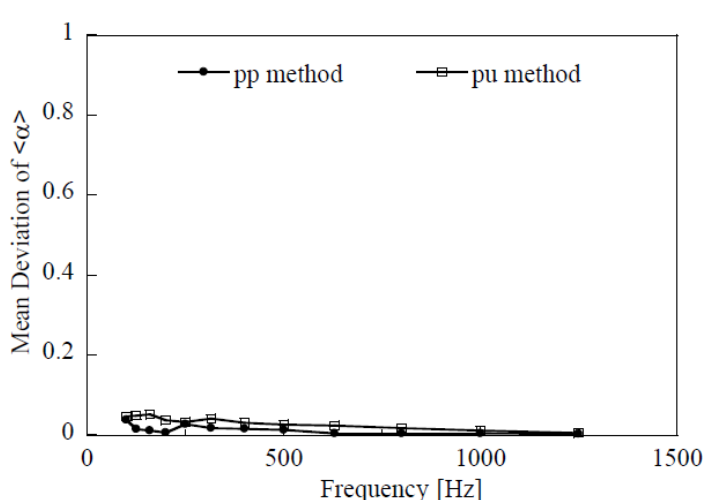

(b)

Figure 6. Comparison of: (a) maximum differences value of absorption coefficients, (b) mean deviation of absorption coefficients of GW50, obtained by proposed method in the corridor, the entrance hall, and the seminar room.

\section{Car Cabin}

In this study, a preliminary measurement using the p-p sensor is conducted in a car cabin to measure the normal surface impedance of carry test sample. Two types of cars are used for the experiment: Car-A; 5-door, 7-passenger minivan with dimensions of $2825 \times 1470 \times 1355 \mathrm{~mm}^{3}$, and Car-B; 5-door, 4-passenger tail wagon with dimensions of $1795 \times 1255 \times 1255 \mathrm{~mm}^{3}$, as shown in Figure 7 . The specimen to be investigated is GW50. The specimen is laid on an acrylic plate and it has dimensions of $0.6 \times 0.3 \mathrm{~m}$. Five conditions were set for the sound source as follows:
a. all doors are closed with ambient noise surrounding the car
$b$. all doors are open with ambient noise surrounding the car
c. one portable sound source added onto condition a
$d$. one portable sound source added onto condition $\mathrm{b}$
e. $\quad$ three portable sound sources added onto condition $b$. 
For comparison purpose, the measurement of a similar sample of GW50 is conducted in Room I using six fixed loudspeakers to radiate incoherent pink noise. The sound absorption coefficients of GW50 measured in Car-A are compared in Figure 8. The corresponding absorption coefficients agree well with the results measured in Room I within the frequencies of 400 to $1200 \mathrm{~Hz}$, except for sound source condition of $a$ and $b$. Moreover, the measurement in Car-B reveals the same basic tendencies of the measured corresponding absorption coefficients as for GW50 (Figure 8(b)), but there are non-negligible differences below $500 \mathrm{~Hz}$. Clearly, the GW50 measured results show distinct fluctuations for sound source conditions $a$ and $b$, which suggests that there is insufficient noise when all doors of Car-A and Car-B are closed. The authors consider that the good agreement shows the plausibility of the method for measuring absorption, because the absorbent tendencies were captured in accordance with the results of Room I when sufficient noise was achieved in the measurement. However, different types of material need to be investigated to support the general applicability and repeatability of our method.

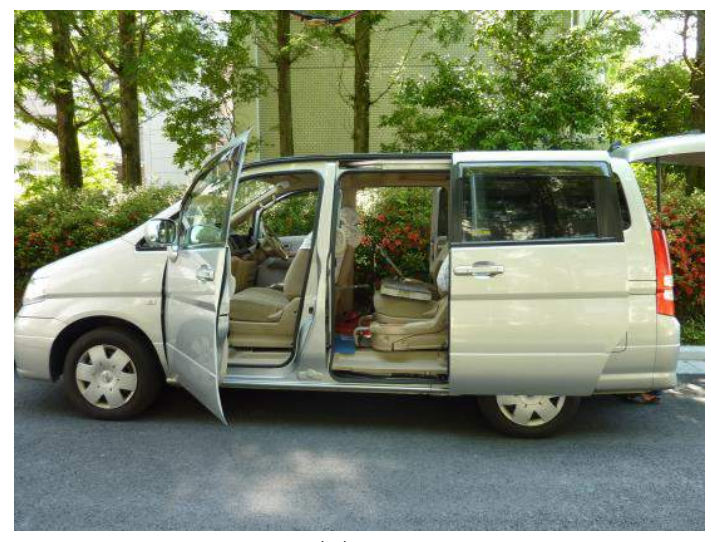

(a)

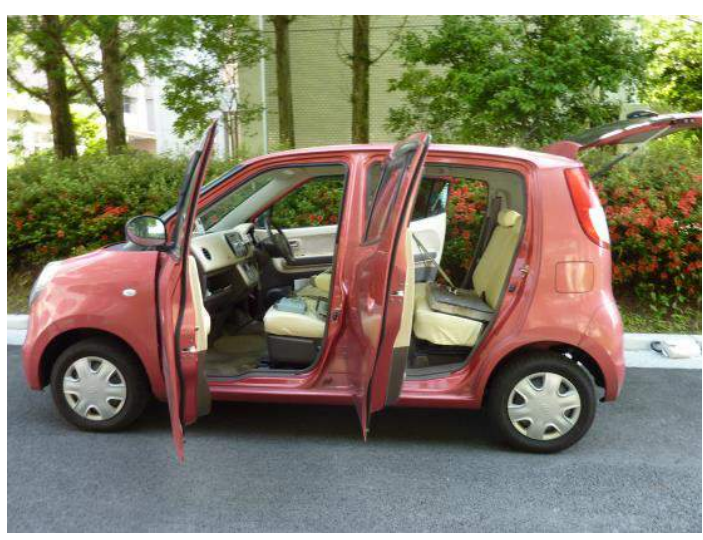

(b)

Figure 7. Two types of car used for experimental purposes: (a) Car-A, and (b) Car-B.

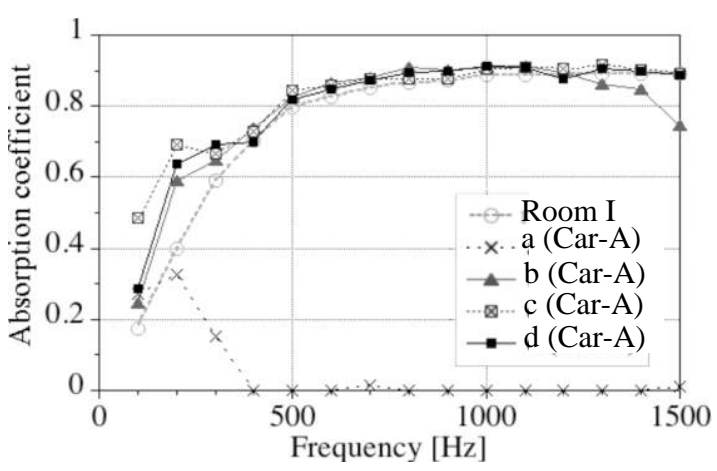

(a)

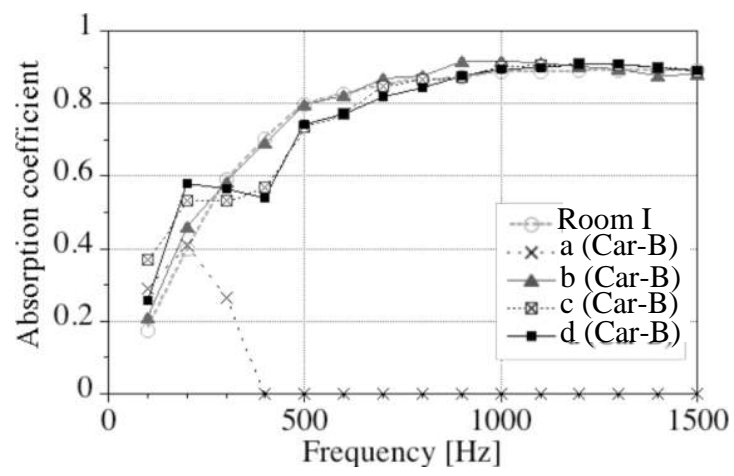

(b)

Figure 8. Comparisons of absorption coefficients of GW50: (a) in Car-A, and (b) in Car-B. 


\section{TRIAL APPLICATION ON DIFFERENT TYPE OF MATERIAL}

\section{Perforated-type Panel}

Direct piercing carved wood panels (DPCWPs) with floral patterns have been used as exterior walls in Masjid Abidin located in Kuala Terengganu, Terengganu, from as early as 1900. The DPCWP with floral pattern is among the most complex forms of DPCWP (Nordin, 2009). Most common DPCWPs with floral patterns are installed with the Daun Sireh motif (DSM). The same procedure of measurement using the $\mathrm{p}-\mathrm{u}$ sensor, as mentioned above, was applied, but the measurements were conducted in an anechoic room with a volume of $58 \mathrm{~m}^{3}$ at Oita University. There are nine types of aperture available for measurement. Figure 9(a) shows the measurement condition for the front view of the DPCWP with DSM. An aluminum frame was used in the measurement to hold the sample in the middle of the room. The dimensions of the sample are $0.37 \times 0.63 \mathrm{~m}$. The foliage of this sample is repeated eight times from a single unit, which comprises nine different types and shapes of aperture, as shown in Figure 9(b).

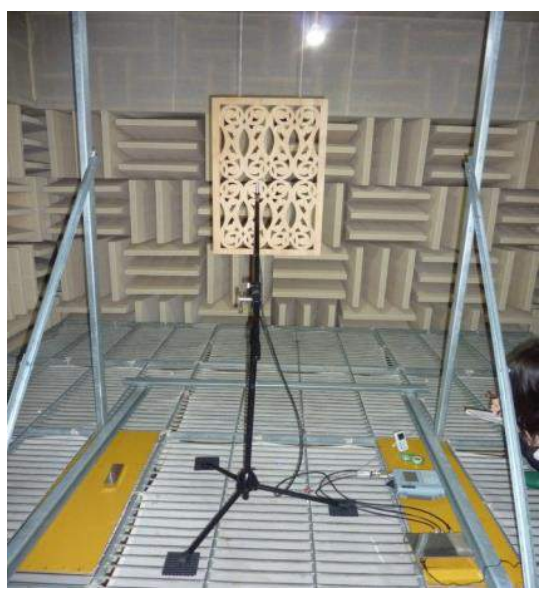

(a)

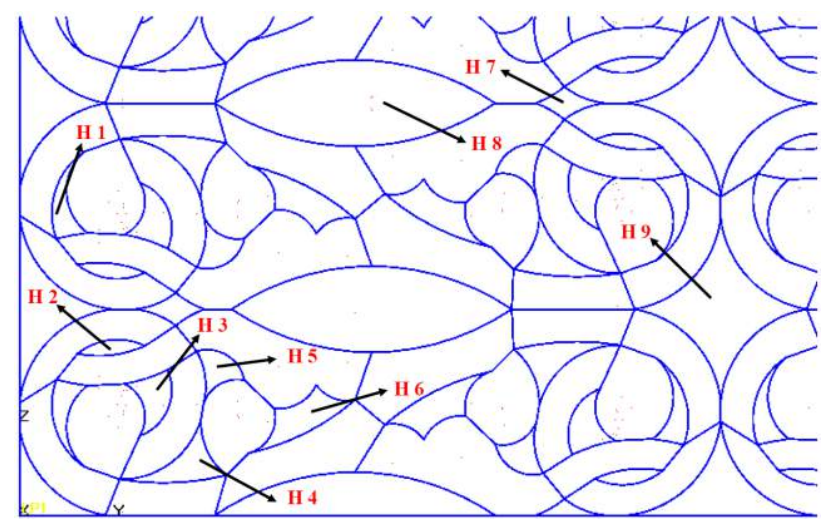

(b)

Figure 9. Measurement condition: (a) DPCWP with DSM inside the anechoic room, and (b) nine types of aperture of the DPCWP.

The measurement of sound absorption characteristics was applied to the DPCWP with $30 \%$ and $40 \%$ perforation ratios. The measurement results for both perforation ratios for the individual apertures are presented in Figure 10. For 30\% perforation ratio, three larger apertures with area of $455 \mathrm{~mm}^{2}(\mathrm{H} 9), 1808 \mathrm{~mm}^{2}(\mathrm{H} 4)$, and $3278 \mathrm{~mm}^{2}$ (H8) have higher absorption coefficients within $750 \mathrm{~Hz}$ and above. The other six smaller apertures with areas in the region of $139 \mathrm{~mm}^{2}$ to $386 \mathrm{~mm}^{2}$ show similar basic tendencies for absorption coefficient values. However, for $40 \%$ perforation ratio, the measured absorption coefficients for all apertures are almost similar from 100 to 800 Hz. The measured absorption coefficients of both perforation ratios are higher when the apertures become larger. For simplicity, all individual aperture results are averaged and presented for both $30 \%$ and $40 \%$ perforation ratios from 100 to $1500 \mathrm{~Hz}$ in Figure 11. The averaged absorption coefficients for both $30 \%$ and $40 \%$ perforation ratios show a significant decrement from 100 to $1500 \mathrm{~Hz}$. It might be readily apparent in the results that the absorption coefficients become higher when the perforation ratio becomes larger. The authors consider that the measured absorption coefficients of the DPCWP 
yield a plausible tendency that supports the feasibility of the proposed method for measuring different types of material.

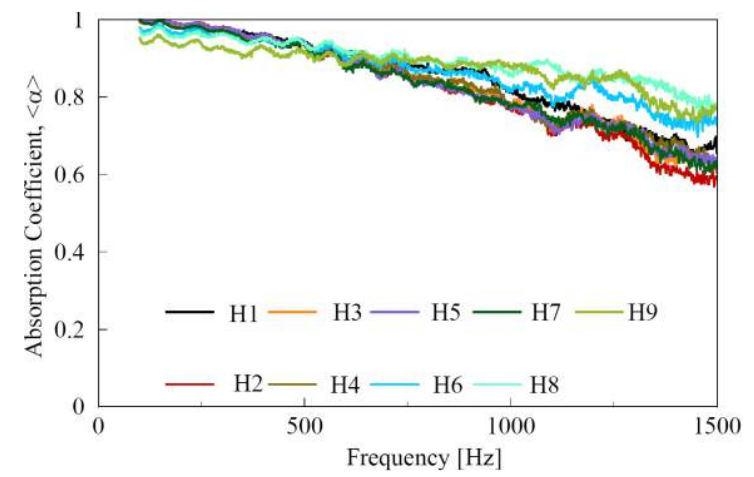

(a)

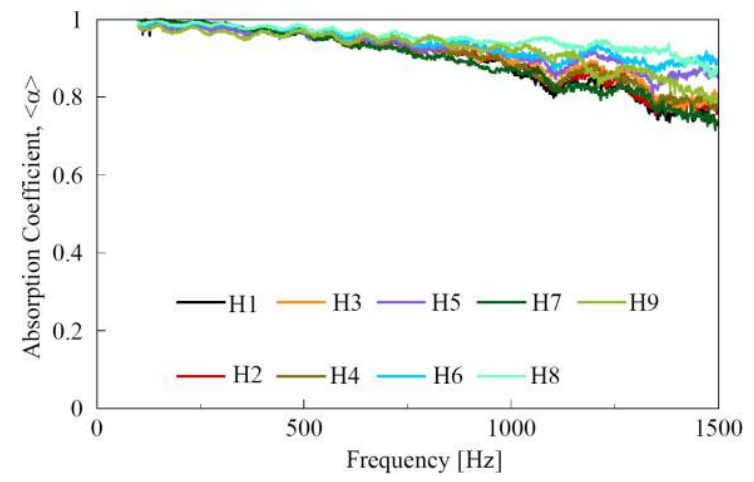

(b)

Figure 10. Sound absorption coefficients of each aperture: (a) $30 \%$ perforation ratio, and (b) $40 \%$ perforation ratio.

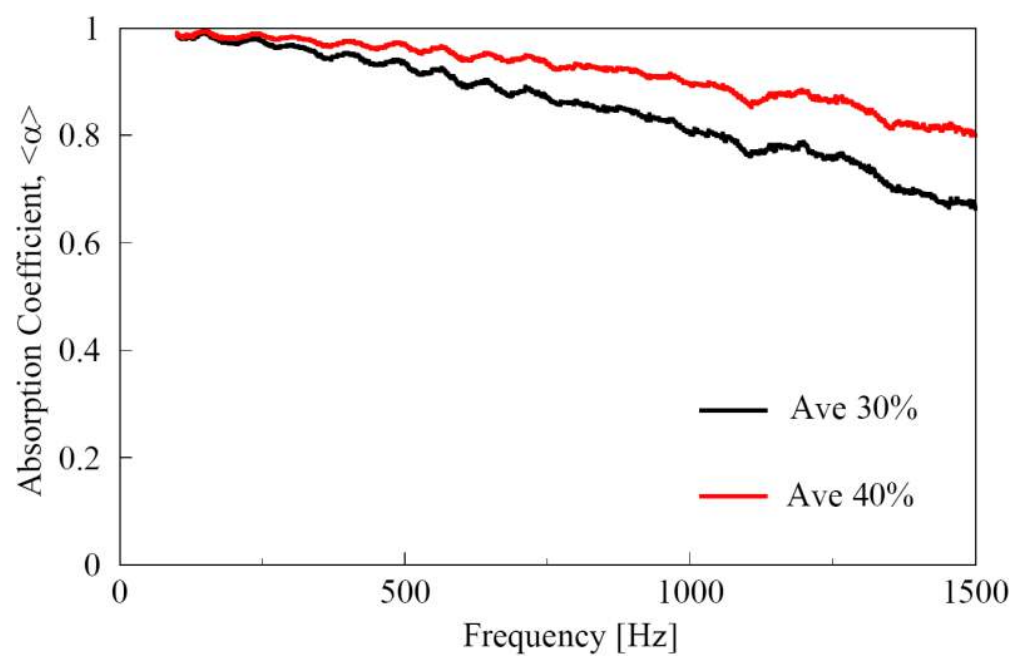

Figure 11. Averaged absorption coefficients obtained using p-u sensor for $30 \%$ and $40 \%$ perforation ratios.

\section{CONCLUSIONS}

Several measurements obtained using methods with $p-p$ and $p-u$ sensors revealed that discrepancies of absorption coefficients attributable to the sensors are small. In this study, the measurements of "ensemble averaged" surface normal impedance at random incidences in different sound fields have been performed. In situ measurements using p$\mathrm{p}$ and $\mathrm{p}-\mathrm{u}$ sensors suggest good applicability of both methods for various practical measurements. Then, we found good agreement between the results obtained by using the p-p method and the values measured in a reverberation room to represent the specimen's sound absorption characteristics in a car cabin. The investigation of DPCWP with DSM showed that larger apertures yielded higher absorption coefficients when a larger perforation ratio was applied. However, both perforation ratios demonstrate an identical decrement of absorption coefficients from lower frequency to higher frequency. Further experimental investigations are now being pursued actively. 


\section{ACKNOWLEDGMENTS}

This research is partially supported by the Japan Society for the Promotion of Science (JSPS), Grant-in-Aid for Exploratory Research, 19656143, and was conducted as one Research Project (A) of the Venture Business Laboratory in Oita University.

\section{REFERENCES}

Allard, J.F. and Champoux, Y. 1989. In situ two-microphone technique for the measurement of the acoustic surface impedance of materials. Noise Control Eng. J. 32(1), 15-23.

Cummings, A. 1991. Impedance tube measurements on porous media - The effect of air gaps around the sample, J. Sound Vib., 151, 63-75.

de Bree, H.-E., Tijs, E. and Basten, T. 2006. Two complementary Microflown based methods to determine the reflection coefficient in situ, Proceedings of the ISMA2006 Conference, Leuven, Belgium, on CD-ROM.

Garai, M. 1993. Measurement of the sound-absorption coefficient in situ: The reflection method using periodic pseudo-random sequences of maximum length, Appl. Acoust. 39, 119-139.

Horoshenkov, K.V., Khan, A., Becot, F.X., Jaouen, L., Sgard, F., Renault, A., Amirouche, N., Pompoli, F., Prodi. N., Bonfiglio, P., Pispola, G., Asdrubali, F., Hubelt, J., Atalla, N., Amededin, C. K., Lauriks, W. and Boeckx L. 2007. Reproducibility experiments on measuring acoustical properties of rigid-frame porous media (round-robin tests), J. Acoust. Soc. Am. 122, 345-353.

International Standard Organization. 2003. ISO 354, Acoustics - Measurement of sound absorption in a reverberation room.

International Standard Organization. 1996. ISO 10534, Acoustics - Determination of sound absorption coefficient and impedance in impedance tubes, Part 1.

International Standard Organization. 1998. ISO 10534, Acoustics - Determination of sound absorption coefficient and impedance in impedance tubes, Part 2.

Iwase, T. and Izumi, Y. 1995. A new sound tube measuring method for propagation constant in porous material - Method without any air space at the back of the test material, J. Acoust. Soc. Jpn. 52, 411-419.

Kosten, C.W., 1960. International comparison measurements in the reverberation rooms, Acustica. 10, 400-411.

Makita, Y., Koyasu, M., Nagata, M. and Kimura, S. 1968a. Investigations into the precision of measurement of sound absorption coefficients in a reverberation room (I) - The $3^{\text {rd }}$ Round Robin Test and the Investigations on Diffusivity of Sound Field, J. Acoust. Soc. Jpn. 24, 381-392.

Makita, Y., Koyasu, M., Nagata, M. and Kimura, S. 1968b. Investigations into the precision of measurement of sound absorption coefficients in a reverberation room (II) - Experimental Studies on the Method of Measurement of the Reverberation and the $4^{\text {th }}$ Round Robin Test, J. Acoust. Soc. Jpn. 24, 393-402.

Nazli bin Che Din, Otsuru, T., Tomiku, R., Okamoto, N. and Asniawaty, K. 2012. Measurement method with a pressure-velocity sensor for measuring surface normal impedance of materials using ensemble averaging: Comparison with other methods and its geometrical configuration, Acoust. Sci Tech. 33, 86-95.

Nordin, N. 2009, Ukiran Kayu Warisan Melayu, first ed., Perbadanan Kraf Malaysia.

Takahashi, Y., Otsuru, T. and Tomiku, R. 2005. In situ measurements of surface 
impedance and absorption coefficients of porous materials using two microphones and ambient noise, Appl. Acoust. 66, 845-865.

Otsuru, T., Tomiku, R., Nazli bin Che Din, Okamoto, N. and Murakami, M. 2009. Ensemble averaged impedance of material using an in situ technique: Preliminary study using boundary element method. Journal of the Acoustical Society of America, 125: 3784-3791. 